\title{
Heroicidad, conquista y el Nuevo Mundo rioplatense. El vacío heroico en el poema épico La Argentina (1602) de Martín del Barco Centenera
}

\section{Heroism, Conquest and the New World on the River Plate. The Epic Poem La Argentina (1602) by Martín del Barco Centenera and its Heroic Vacuum}

\section{DIRK BRUNKE}

Romanisches Seminar

Ruhr-Universität Bochum

GB 7/148, Fachnummer 148, Universitätsstraße 150

Bochum, 44801. Alemania

dirk.brunke@rub.de

Orcid ID 0000-0003-1851-6403

Resumen: La Argentina (1602) es la primera y única epopeya renacentista rioplatense. Con su trabajo, el arcediano Barco Centenera crea uno de los textos fundacionales de esa región. Sin embargo, el texto no forma parte del corpus tradicional de los textos épicos del Siglo de Oro; solo recientemente se han publicado cada vez más trabajos sobre ese curioso poema épico. Aunque el poema épicoheroico carece de un héroe central, la elección del género épico no es incidental. Mediante un análisis retórico y semántico se argumenta que la falta de heroicidad (vacío heroico) genera un potencial para la cuestión de la heroicidad en el tiempo de la conquista que se combina con el tópico de lo maravilloso del Nuevo Mundo. Sigue un análisis del discurso narrativo con foco especial en la reflexividad.

Palabras clave: Barco Centenera. Heroicidad. Poesía épica. Reflexividad. Maravilloso.
RECIBIDO: 19 DE FEBRERO DE 2018 ACEPTADO: 12 DE MAYO DE 2018
Abstract: La Argentina (1602) is the one and only Renaissance epic poem from the River Plate. The author Martín del Barco Centenera provides with his epic poem one of the foundational texts of this region. Nevertheless, it does not belong to the traditional corpus of epic texts from the Siglo de Oro; an ever-increasing number of studies have been published only recently. Although this epic-heroic poem lacks the figure of a central hero, the decision to write an epic poem is not accidental. By means of a rhetorical and semantic analysis, this paper argues that the lack of epic heroism (vacío heroico) generates potential to discuss the question of heroism in times of the conquest. Barco Centenera wittingly combines this discourse with the topos of the marvellous of the New World. An analysis of the narrative discourse with a special focus on its reflexivity complements the argument.

Keywords: Barco Centenera. Heroism. Epic Poetry. Reflexivity. Marvellous. 


\section{INTRODUCCIÓN}

E 1 clima heroico que supuso la "gesta de la conquista" (Peña 295) promovió un extraordinario desarrollo de la poesía épica en el Nuevo Mundo. Ya Menéndez y Pelayo constató que las tres mejores epopeyas modernas en lengua española -Ercilla y Zúñiga: La Araucana (1568/1578/1589), Diego de Hojeda: Cristiada (1611), Bernardo de Balbuena: El Bernardo (1624)- fueron escritas en el continente americano o tematizan la conquista del Nuevo Mundo (Carilla 302). Ercilla, el poeta soldado por excelencia, que participó en las batallas de la conquista de Chile y transformó en versos épicos sus impresiones, crea con La Araucana la paradigmática epopeya americana. La recepción y el éxito de la obra fueron inmediatos: "apasionó a los españoles que se establecieron en América porque en ella vieron el primer monumento literario dedicado a la conquista" (Serna 23). Esa obra maestra no solo sirvió de fuente de información historiográfica a los humanistas. Es más significativo mencionar que a ese poeta soldado le siguió una enorme retaguardia: Juan de Castellanos y sus Elegías de varones ilustres de Indias (1589) y el Arauco domado del chileno Pedro de Oña (1596) son solo dos de los muchos textos que toman la epopeya de Ercilla como modelo en el sentido de la imitatio y que fundaron la rica tradición épica en la Nueva España, la Nueva Granada y en el Perú (Chang-Rodríguez 34-35).

En la misma época, la situación de la poesía épica al otro lado de los Andes -en el territorio que a partir de 1776 se llamaría Virreinato del Río de la Plata- es completamente diferente. El único poema épico sobre la conquista de esa región periférica es la Argentina y conquista del Río de la Plata (1602) de Martín del Barco Centenera (1535-¿1605?). Ese arcediano extremeño llega al Nuevo Mundo en 1572 con la expedición de Juan Ortiz de Zárate. Fue capellán de la expedición de ese general y pasará veintiún años en América, nueve de los cuales en la cuenca rioplatense. En su poema épico de más de diez mil versos endecasílabos, agrupados en veintiocho cantos y escritos en octavas reales, Barco Centenera transforma la historia del descubrimiento, de la conquista y poblamiento del Río de la Plata y del sur de Brasil en poesía y encuadra su texto en la prestigiosa tradición de la poesía épica sobre la conquista del Nuevo Mundo.

Como la forma que se escoge es, en la Primera Edad Moderna, fundamental para la producción de sentido (Beauchesne 220), se analizará la estructura y la retórica del texto, así como el discurso narrativo sobre los conquistadores y los enemigos del imperio, con un foco especial en la heroicidad y su 
configuración en el texto. El tópico de lo maravilloso del Nuevo Mundo es el denominador común de todos los discursos. El punto de partida de nuestro análisis es el proemio.

\section{EL VACÍO HEROICO}

La estructura de la obra de Barco Centenera se corresponde en muchos puntos con las exigencias de los preceptistas épicos. Aparte del ya mencionado uso estricto de la octava heroica, se trata de un poema narrativo dividido en cantos, de tema histórico y guerrero que, además, empieza con un proemio épico. El nombre, La Argentina, indica su filiación a la epopeya clásica, como, por ejemplo, la Odisea o la Eneida (Tieffemberg 1997, 368). Falta mencionar que el discurso narrativo tiene una dimensión marcadamente autorreflexiva; aspecto casi imprescindible de la épica posariostesca (Hempfer). Volveremos a ese punto más adelante, pero antes es necesario investigar detenidamente el eje central de la poesía épica: en el sentido clásico del género, debe tratarse de "un poema nacional que exalte en la figura del héroe valores considerados trascendentes" (Tieffemberg 1997, 368), es decir, que el héroe figura como la encarnación y la revelación de valores fundacionales o constituyentes de una colectividad. El héroe es el centro de la acción heroica. No vamos a indagar más en la cuestión de la nacionalidad -tarea vana considerando el concepto de identidad en la Primera Edad Moderna-. Pero la cuestión del héroe, de la heroicidad y de la configuración heroica del protagonista nos ocupará a continuación.

En la épica americana, sobre todo novohispana y cortesiana, el protagonista se estiliza como héroe en la medida en que es el fundador del nuevo imperio colonial. En muchos casos adquiere características hasta sobrehumanas, como, por ejemplo, en el primer poema épico sobre el descubrimiento y la conquista del Nuevo Mundo que se publica: En los cantos XI-XV de Carlo famoso (1566) de Luis Zapata (1526-1595), Cortés narra sus hazañas y no se configura como hombre de carne y hueso: "He is capable of overcoming monsters such as gigantic eagles and sharks in order to protect and win the respect and veneration of the indigenous population" (Mazzotti 7). La temprana épica americana muestra lejanas resonancias del mundo de los libros de caballerías, de sus hazañas y protagonistas prodigiosos. En cuanto al héroe épico del Arauco domado, de Pedro de Oña, Mazzotti hace hincapié en que es el centro de atención del inmenso texto, "revealing of the world a vision of martial heroism principally centered on the individuality of the protagonist" (8). En los 
dos casos, Mazzotti subraya el vínculo fundamental entre poesía épica y el discurso oficial de poder: "The poetic heroization of military leaders also played its part as political affirmation" (5). Puesto que el héroe épico de la conquista es un individuo dotado de fuerza sin igual que representa y justifica la causa imperial de la conquista -tal como se define la épica desde la Antigüedad (ver Quint)-, ¿cómo se configura el héroe en el único poema épico rioplatense de esa época?

Desde el famoso "Arma virumque cano" de Virgilio hasta el proemio de Ercilla, "el valor, los hechos, las proezas / de aquellos españoles esforzados" (I, I, 5), los versos iniciales son el lugar privilegiado para anunciar el tema y los protagonistas del texto. Ese elemento fundamental de la poesía épica -propositio- también influye en la estructura de nuestro poema rioplatense. Sin embargo, las guerras y proezas -imprescindibles para la estilización de héroes épicos- solo aparecen como un elemento temático entre muchos otros:

Haré con vuestra [Apolo] ayuda este cuaderno

del argentino reino recontando

diversas aventuras y estrañezas, prodigios, hambres, guerras, y proezas. (I, 2)

Aunque la voz épica proclama aquí que cantará guerras y proezas, la propositio, por un lado, indica que el discurso narrativo concederá lugar a temas poco épicos -el hambre- y, por otro lado, anuncia que se cantarán extrañezas y prodigios. Las guerras y proezas son más bien el apéndice de la enumeración de los distintos temas. Como vemos más adelante, Barco Centenera no intenta cantar hechos prodigiosos y neo-caballerescos como, por ejemplo, Zapata en su epopeya. Más bien, las 'estrañezas y prodigios' de la propositio anuncian que el texto tematizará lo que en la primera Edad Moderna se denominó lo 'maravilloso' del Nuevo Mundo (ver Greenblatt), es decir, el asombro que causaron la naturaleza y los indígenas recién descubiertos. Además, la rima 'estrañezasproezas' insinúa que Barco Centenera intenta una combinación ingeniosa del tema heroico y lo maravilloso. Esa combinación adquiere una dimensión semántica más amplia y, sobre todo, constitutiva del texto. De todas formas, un análisis de la propositio muestra que la voz épica proclama que su discurso narrativo será politemático y que se desviará en parte de la temática épica central, la heroicidad.

1. Cito de la edición a cargo de Silvia Tieffemberg. 
A renglón seguido el lector se ve confrontado con personajes que no se corresponden con los héroes sobre los cuales suele cantar la epopeya. Los generales de ejército y los conquistadores que aparecen en La Argentina -Pedro de Mendoza, Juan Ortiz de Zárate y Juan de Garay- no combaten en nombre del imperio y no tienen motivos trascendentes para conquistar el territorio desconocido. A Juan Ortiz de Zárate, por ejemplo, se lo describe como un hombre entre muchos, llevado al Nuevo Mundo por su codicia: "ensáyase el metal y plata fina / se saca, que movió a los codiciosos, / y entre ellos Joan Ortiz" (VI, 19).

Esa descripción poco heroica y que aporta poco prestigio a la figura del conquistador culmina en el undécimo canto. Durante una hambruna en la isla de Santa Catarina un grupo de soldados sufre las consecuencias del comportamiento de Juan Ortiz; como no proveyó sus soldados de armas, esos son presa fácil para los enemigos:

vencido de sus vanas pretensiones, no tiene los soldados guarnecidos, las armas les quitó en ocasiones las vuelve, [...] que no son ya de provecho, que el moho y el orín las ha deshecho. (XI, 10)

Con su comportamiento, Juan Ortiz impide incluso el desarrollo de la conquista. Sobre todo, no es el único conquistador que el narrador épico describe como personaje codicioso y poco interesado en la causa de la conquista. La codicia se convierte en un verdadero leitmotiv del texto -y de la literatura colonial en general- y se atribuye a casi todos los representantes del poder imperial. En general, el lector no va a encontrar personajes

que desempeñan el papel del héroe, [y] tampoco existen enfrentamientos bélicos de magnitud ni jefes que lleven adelante tácticas militares. La conquista rioplatense no se percibe en la obra como una acción coherente y homogénea del imperio, sino como una lucha por el poder entre los mismos españoles. (Tieffemberg 1997, 371)

Así pues, la modesta promesa heroica de la propositio no solo no se cumple, sino que se invierte en un discurso crítico sobre los motivos de los agentes de la conquista.

La desmesurada codicia relativiza la estilización heroica de los conquistadores. Aparte de ese leitmotiv, el tema del hambre es el segundo eje central 
del texto que impide una configuración heroica. Por supuesto, ese tema es referencial ya que los colonizadores de la cuenca rioplatense tenían que luchar contra las condiciones naturales adversas y poco favorables para una alimentación sustentable. Adicionalmente, el tema del hambre se usa en un sentido metafórico y se emplea como símbolo de la ambición y de la codicia de los oficiales. Esa hambre de riquezas y poder es la primera manifestación de intertextualidad en la literatura rioplatense, ya que el tópico del hambre recorre el primer texto escrito en y sobre esa región -el romance elegíaco de Luis de Miranda (hacia 1540) - como un hilo conductor (Curia 84) y se entiende como castigo divino para la codicia (Tieffemberg 2017). Así pues, el hambre como tema central de los textos fundacionales de la literatura rioplatense funciona como el denominador común y crea la imagen de un destino compartido de la cuenca rioplatense que problematiza la 'heroización' de la historia de esa región periférica. Los protagonistas del poema épico de Barco Centenera "no luchan por valores trascendentes, sino por sus propias ambiciones: son intemperantes, lujuriosos y ávidos de beneficios pecuniarios" (Tieffemberg 1997, 370). El verdadero enemigo contra el que tienen que luchar los 'conquistadores' es el hambre. ¿Cómo evaluamos esas observaciones en cuanto a la heroicidad del texto?

Aunque el proemio anuncia un texto politemático que probablemente se desvía de la temática épica, la propositio también estimula expectativas prototípicas de la épica: guerras y proezas de los conquistadores españoles. En cuanto a la estructura, el autor cumple con las exigencias del género épico. No obstante, el discurso narrativo carece de una figura central y heroica que represente la ideología del imperio. Barco Centenera toma el molde épico, pero no lo llena con un discurso heroico; las expectativas estimuladas por el proemio se disuelven en un vacío heroico.

Mientras que la promesa de una narrativa heroica sobre los hechos de los españoles no se cumple, la voz épica retoma muchas veces el otro aspecto central de la propositio, las "diversas aventuras y extrañezas/prodigios”. Mencionamos anteriormente que leemos esos versos como un programa politemático que incluye lo maravilloso del Nuevo Mundo y que lo conecta -tal como la rima del proemio "extrañezas / proezas"- con la propositio heroica. Esa observación es significativa porque acabamos de constatar que el texto se caracteriza por un vacío heroico en cuanto al discurso sobre los españoles. Después de todo, queda por mencionar que Barco Centenera, aparte del vacío heroico, usa ciertos elementos del discurso épico para mostrar como héroes a personas que 
-punto central de La Argentina- en otras ocasiones hubieran sido condenadas a papeles marginales o incluso al olvido porque se trata de los enemigos del imperio.

Barco Centenera tematiza, por ejemplo, los enfrentamientos con los corsarios ingleses (Francis Drake y Thomas Cavendish) que amenazaron la costa del sur (Chile/Perú) en la segunda mitad del siglo XVI. Veamos en las siguientes citas de los cantos XXI y XXII cómo describe al más notorio de los piratas enemigos del imperio:

Y pues se han de contar maravillosas

hazañas del corsario más grandioso

que escriben las historias más famosas,

y más determinado y venturoso;

conviene que pongamos tales cosas

en un canto por sí maravilloso,

pues puso en maravilla a nuestra España

el capitán Francisco y su hazaña. (XXI, 52)

$\mathrm{Y}$ así justo será que por olvido

no deje yo a Francisco y su gran hecho,

pues que en aquestos tiempos ha venido

al Perú de su tierra muy derecho, [...]

contando en breve suma esta hazaña

que es digna de contarse por extraña. (XXII, 2)

La retórica de esas octavas es muy reveladora en cuanto al discurso heroico del texto. El uso repetitivo, en el canto XXI, de "más" y "maravilla/maravilloso" le da a la octava un tono hiperbólico e irónico. La ironía -estrategia narrativa central del texto- se concretiza aquí por las rimas "España-hazaña" y "hazañaextraña”. La rima, en el sentido retórico, subraya por vía de homofonía una similitud, inesperada e insólita, entre dos cosas. En cuanto al discurso (políticoimperial) oficial, esas rimas se implementarían para subrayar las proezas de los conquistadores como representantes del imperio español. En el caso barcocenteneriano, sin embargo, el narrador modifica la rima combinándola con el aspecto de lo maravilloso: No son los españoles quienes producen hazañas y quienes se ven confrontados con lo maravilloso del Nuevo Mundo, sino que es el enemigo del imperio quien maravilla a los españoles mediante sus hazañas. Francis Drake, en otro canto del poema, hasta "aparece descrito como un verdadero héroe" (Ortiz Gambetta 77) y el poeta "se inclina abiertamente por 
resaltar figuras que no deberían ser los personajes centrales de la conquista imperial" (77).

En todo caso, esas rimas ilustran paradigmáticamente que Barco Centenera invierte, en general, el discurso heroico-épico tradicional y, en particular, el discurso sobre los piratas ingleses. ${ }^{2}$ Al fin y al cabo, la rima final de la octava del canto XXII conecta con el proemio del poema y subraya, una vez más, que lo que se anuncia en la propositio se realiza mediante la combinación ingeniosa de dos campos semánticos: por un lado, la heroicidad expresada por el uso continuo de palabras como "hazaña", "proeza" y "héroe"; por otro lado, la isotopía de lo maravilloso, constituida por el uso intensivo de palabras como "extrañeza", "prodigios" y "maravilla". Esos dos campos semánticos son fundamentales para el discurso narrativo del texto ya desde el proemio.

Aparte de la retórica, vale la pena agregar que esas estrofas explicitan bien la autorreflexividad del discurso narrativo. El narrador hace explícito el tema de su texto porque se ve forzado a justificar la tematización de los hechos -hazañas- del enemigo. La necesidad de justificar la tematización de Drake se revela tomando en cuenta que la poesía épica -igual que la historiografía oficial, a la que alude en el verso "que escriben las historias más famosas"- forma parte del discurso oficial del imperio colonial que fue, sobre todo, un discurso afirmativo del poder. Cantar al corsario enemigo, marginado por el discurso oficial y condenado por la política, sale de la norma del discurso épico e historiográfico (oficial). Refiriéndose a la historiografía oficial y al discurso del poder en la primera Edad Moderna, Barco Centenera alude al aspecto de que la épica y la historiografía fueron los géneros literarios para fijar en la escritura los acontecimientos históricos. En otras palabras, el narrador pone énfasis en la verosimilitud de su discurso épico que se basa en el hecho de que Barco Centenera es uno de los testigos oculares de la conquista del Nuevo Mundo rioplatense.

2. En su exitoso poema épico La Dragontea (1598) -sobre la derrota y muerte de Francis Drake en Panamá-, Lope de Vega cumple con el discurso político oficial y estiliza el corsario protestante como supremo enemigo del imperio (Friedlein 347). Aparte de los textos que afirman la empresa imperial de España, existe un grupo de textos coloniales que cuestiona o socava ese discurso de un imperio triunfal. En el caso de la épica baste mencionar La Araucana. El poema de Ercilla y Zúñiga se caracteriza por su discurso narrativo ambiguo, ya que coexisten una defensa de la Conquista y la idealización de los líderes mapuches. En todo caso, Barco Centenera no pretende erigirse como portavoz del discurso político-imperial oficial. 


\section{EL NARRADOR ÉPICO AUTODIEGÉTICO Y AUTORREFLEXIVO}

Como ya vimos en las citas anteriormente analizadas, hay una fuerte presencia de un yo narrador. Igual que en otros poemas épicos (p. ej. La Araucana) o textos historiográficos (p. ej. los Comentarios reales del Inca Garcilaso) de la época, el yo es el punto de partida y la garantía de autenticidad de los acontecimientos narrados. En nuestro caso, el fuerte discurso del yo es el otro factor que llena -con sus pasajes autodiegéticos y autorreflexivos- el vacío heroico del texto.

Para captar mejor la autodiegesis del texto, es necesario mencionar las incontables anécdotas que Barco Centenera entreteje en su poema y que contribuyen decididamente al tono humorístico y hasta burlesco (Ortiz Gambetta 71). En el canto XVII, por ejemplo, la voz épica narra su visita, durante otra hambruna, en la casa de una viuda. Cuando entra, la vieja le muestra el cadáver de un perro que ella acaba de matar. Era el perro de su esposo recién muerto:

entró este [el perro] un día en su posada, mas nunca más salió de aquel empeño porque ella le mató de una porrada al tiempo del entrar, con un gran leño; mostrándolo me dice "¿Qué haremos?", yo dije: "Asa, señora, y comeremos". (XVII, 53)

La anécdota no solo ilustra bien el tono humorístico del texto y la omnipresencia del motivo del hambre, sino que más bien ejemplifica que lo anecdótico ocupa un lugar privilegiado en el texto. Siempre que se trata de las cosas más fundamentales de la vida cotidiana -la alimentación-, Barco Centenera incluye estos relatos breves y humorísticos de sucesos curiosos. Sirven de ejemplo o ilustración de la problemática de la conquista y, sobre todo, lo hacen desde una perspectiva individual, subjetiva, poco heroica, en suma, subalterna. La historia personal e individual llena el vacío heroico concediendo espacio a la microhistoria. Campra entiende este aspecto central del poema como el intento de dar un "tono de cotidianeidad" a los aspectos más esenciales de la vida en la temprana colonia. Es decir que "la situación real de la colonia se manifiesta con más eficacia que en las historias oficiales” (1992, 291). ${ }^{3}$

3. Es interesante mencionar que los románticos rioplatenses, sobre todo Juan María Gutiérrez, propusieron que el valor historiográfico de la obra de Barco Centenera se basase justamente en ese aspecto subjetivo e individual de las anécdotas (Gutiérrez). Desde el punto de vista de la estética romántica, la perspectiva autodiegética cumple con la autenticidad, concepto tan apreciado por los románticos y su búsqueda de la verdadera poesía autóctona. 
Hay que subrayar que la situación real de la colonia, tal como se narra en las anécdotas, es un desafío para las ambiciones épicas y, por ende, para el género épico en esa región periférica del imperio: en la época después de la conquista exitosa de los imperios de los aztecas y los incas, con las toneladas de metales y piedras preciosas llevadas al Viejo Mundo, las expectativas de los conquistadores del Río de la Plata se nutrieron de los cuentos maravillosos de la riqueza de Tenochtitlán y del Tahuantinsuyo, de la promesa de guerra y honor. Las esperanzas de un resultado semejante en el Río de la Plata, sin embargo, se disolvieron ante la situación real de esa región y la conquista rioplatense "se salda con una serie de desilusiones, no solo en el plano económico, sino también en el bélico, pues no se encuentran como adversarios imperios consolidados y fastuosos sino tribus más o menos nómadas" (Campra 1997, 377). Además, la consolidación de Buenos Aires como colonia permanente tardó más de cincuenta años ya que hubo varias destrucciones. Todos ellos son aspectos que "desprestigian el discurso heroico de las grandes hazañas exitosas" (Beauchesne 218), hecho que se refleja en el poema épico barcocenteneriano por la ausencia casi absoluta de heroicidad. Al fin y al cabo, el vacío heroico deja espacio para la tematización (anecdótica) del lado más oscuro de la conquista. La autodiégesis lo presenta de forma inmediata y directa y con un punto de vista subalterno del narrador autodiegético que de ningún modo corresponde con el discurso épico tradicional, es decir ennoblecedor, y oficial, es decir ensalzador y afirmativo del poder.

Para mejor ilustrar que Barco Centenera se desvía del discurso oficial mediante su visión individual y personal del mundo rioplatense, queremos mencionar el canto en que tematiza la expedición de Álvar Núñez Cabeza de Vaca. El narrador representa ese conquistador y oficial como una persona que no persigue los quiméricos tesoros de oro y riquezas de los que se nutre -tal como lo expresa el discurso narrativo del texto- la motivación de los otros conquistadores. Durante una expedición, así lo cuenta Barco Centenera, y justamente cuando un indio le habla de una ciudad llena de riquezas, Cabeza de Vaca decide volver porque los soldados se están muriendo de hambre:

y sin hallar noticia de oro o mina, con barcos y navíos fue subiendo trescientas y más leguas, pues camina hasta saber de plata, pero viendo que la rabiosa muerte andaba suelta, por no perder su gente dio la vuelta. $(\mathrm{x}, 17)$ 
De entre las muchas figuras codiciosas, Cabeza de Vaca se destaca por su carácter benévolo. Esa representación es tan importante porque hubo, en aquel entonces, una polémica sobre el adelantado que ya había vuelto a España por orden del Rey, acusado de infidelidad. En La Argentina, sin embargo, el narrador "expresa claramente su postura favorable hacia Cabeza de Vaca" (Beauchesne 224), enalteciéndolo y glorificándolo. Cabeza de Vaca se representa "como alternativa al modelo del héroe militar ideal que busca y logra alcanzar su objetivo" (231). Con esa "resemantización de la aventura de Álvar Núñez Cabeza de Vaca" (218), el texto asume una función claramente política, explotando el género épico para ennoblecer una figura que en otros contextos se marginaliza por traidor.

Constatamos, pues, que el discurso autodiegético complementa la historiografía rioplatense aportando una visión subalterna de la vida colonial. El texto de Barco Centenera narra el desengaño heroico y lo vierte en el molde de un poema épico, llenando el discurso heroico con su visión subjetiva de los acontecimientos. El discurso autorreflexivo del narrador autodiegético, ahora, da al texto un eje central y ordena el discurso heterogéneo bajo una visión subjetiva. Empleamos el término de visión subjetiva no solo porque el texto es autodiegético y autobiográfico, sino también en el sentido de que la visión del Nuevo Mundo rioplatense no corresponde al discurso épico oficial y predominante de la época, lo que conllevaría una correspondencia en la relación entre épica y poder, glorificando y ennobleciendo los sucesos de la conquista.

Aparte de esa visión subjetiva y ajena al discurso oficial, el narrador llena el vacío heroico con párrafos autorreflexivos en el más estricto sentido de la palabra. Es decir que el narrador, desde la tercera estrofa del poema hasta el fin, desarrolla un discurso en que autotematiza lo que está haciendo, el acto de escribir y la génesis del texto:

Tratar tengo también de sucedidos y estraños casos que iba yo notando, de vista muchos son, otros oídos, que vine a descubrir yo preguntando, de personas me fueron referidos a quien comunicaba, conversando de cosas admirables, codicioso saber, por escribirlas deseoso. (I, 3)

A mí me cupo en suerte esta jornada, que, de saber y ver muy desseoso, 
jamás dexé entrar qualquiera entrada, aunque fuesse el peligro temeroso. (XII, 8)

A diferencia de los desmesurados intereses pecuniarios de los conquistadores, el narrador reclama el leitmotiv de la codicia para sí mismo y lo transforma en metáfora del afán humanista del saber ("codicioso/saber", "de saber y ver muy desseoso"), estimulado por el descubrimiento del Nuevo Mundo y de sus "cosas admirables". Ante la realidad desengañadora de la conquista rioplatense, lo único que sostiene la decisión y la capacidad de superar las dificultades elementales -el hambre- es "cuando se trata de empresas de conocimiento, es decir, las que procuran material para la escritura" (Campra 1997, 384). La autotematización de la escritura forma uno de los ejes temáticos que más impregnan el discurso autorreflexivo.

En otras ocasiones, ese discurso autorreflexivo se vuelve más general y medita sobre el papel fundamental de la escritura para la conquista. Tomando el modelo clásico de exemplum, Barco Centenera inserta breves relatos que sirven para ilustrar la importancia de la escritura en la primera época colonial y el sistema de administración. En el canto XVII, por ejemplo, resume los sucesos que resultaron en el aprisionamiento de Túpac Amaru (1572), último rey de los incas. El virrey Francisco de Toledo ordena que el prisionero sea degollado. El licenciado responsable de la ejecución de tal orden pide explícitamente una orden escrita. Si no se le entrega la orden en forma escrita, la sentencia no se realiza. Correspondiendo al discurso oficial del poder, el discurso autorreflexivo del texto ilustra el poder de la escritura para la consolidación y el mantenimiento del imperio en todo cuanto se entiende como acto o proceso jurídico: desde el contrato que firmó Colón con los Reyes Católicos hasta el proceso jurídico de Las Casas y el caso del Inca Garcilaso, la conquista de América se basa en los escritos jurídicos de los agentes de la época. Entendemos el discurso sobre el poder de la escritura como una alusión al carácter desengañador de la conquista del Río de la Plata que -punto central de nuestro argumento- sirve para ilustrar que, al lado del aspecto guerrero y heroico, el afán de saber y escribir juega un papel cada vez más importante en la primera Edad Moderna. En todo caso, el discurso del texto barcocenteneriano retoma el tradicional concepto de 'armas y letras', desheroizando las armas y glorificando las letras.

No obstante, aunque hay párrafos en los que la escritura aparece como medio favorable y promovedor de la conquista y del poder, el texto de Barco Centenera es más bien una meditación sobre el potencial de la escritura ante 
el desengaño de las expectativas de los conquistadores y ante la realidad inesperada del Nuevo Mundo rioplatense. Barco Centenera presenta esa realidad mediante las muchas anécdotas, leyendas y episodios curiosos que no corresponden a las exigencias del género épico-heroico y que llenan el vacío heroico. Esa heterogeneidad discursiva ilustra bien la desilusión de las expectativas y demuestra así que ese texto es uno de los pocos ejemplos de la épica renacentista en que la realidad del Nuevo Mundo no se describe -a causa de las expectativas literarias e ideológicas del escritor- como un mundo maravilloso que solo el conquistador sobrehumano es capaz de captar. Lo maravilloso se emplea más - tal como vimos en la retórica del pasaje sobre el pirata enemigopara formar un discurso que sale de la norma. Mientras que en la épica novohispana y cortesiana los protagonistas se transforman en superhéroes que saben enfrentar exitosamente los desafíos y peligros del Nuevo Mundo maravilloso, el texto rioplatense intenta dibujar un cuadro poco ennoblecedor.

La ya mencionada heterogeneidad discursiva del texto expresa un cierto grado de inseguridad en cuanto a la percepción del Nuevo Mundo (rioplatense). $\mathrm{O}$, visto desde otro ángulo, el texto es un ejemplo muy temprano de que, en los escritos sobre América, surge un imaginario americano-rioplatense, que, en el siglo XVII, sigue en proceso de creación y que desafía la percepción eurocéntrica. Como ya hemos visto, el cuadro realista del texto no corresponde a las expectativas heroicas porque la realidad de la cuenca rioplatense no corresponde a lo que se esperaba encontrar en América. Ya hemos mencionado que el discurso autorreflexivo pone énfasis, por un lado, en el impulso de escribir sobre cosas hasta entonces desconocidas y, por otro lado, en la experiencia individual y singular del narrador. El narrador es el testimonio de "una realidad no solo no codificada (como en el caso de Bernal Díaz), sino también resistente a las tentativas de codificación" (Campra 1997, 382). En la épica tradicional sobre la Conquista y el descubrimiento se describía el Nuevo Mundo con una mirada europea, utilizando esquemas tradicionales de percibir, describir y entender el mundo. Es decir que la percepción del Nuevo Mundo bajo conceptos importados de Europa resulta en una desilusión. Barco Centenera asegura haber oído, por ejemplo, el canto de las sirenas en una isla del Río de la Plata. Mientras que en la Antigüedad ese canto atrae a los hombres, el canto sireno-rioplatense no es atrayente; más bien, así lo describe el autor, parece un lamento.

Destacamos que Barco Centenera es, supuestamente, el primer autor que usa el topónimo "La Argentina" para referirse a una cierta región geográfica 
(ver Rosenblat) y para darle un nombre propio. El yo épico, desde el inicio del poema, habla de "nuestra Argentina" y, refiriéndose al Río de la Plata, usa el epíteto "el nuestro". Es importante mencionar que la percepción de la naturaleza -como el ejemplo de las sirenas rioplatenses ya indica- sigue ese modelo de percibir con una mirada europea y, al mismo tiempo, deconstruir esa mirada ante la realidad desengañadora. Basta mencionar la descripción del río, que se compara con el mítico Nilo:

Del rio Nilo escriben scriptores

Lo mesmo pero es tanta la grandeza

De aqueste y de sus braços, que mayores

Los juzgo que no estiman la braveza

Del Nilo en tanto grado los autores,

Y si del Nilo fuera la estrañeza

Tan grande como deste, y se escriviera

$\mathrm{Al}$ mundo admiración mayor pusiera. (I, 36)

El intento de glorificar el río como un río épico se contrasta con el vacío heroico. La realidad rioplatense no cabe en el esquema europeo de percibir el mundo, lo que resulta en una incertidumbre de la percepción. El autor se ve confrontado con un mundo nuevo que le estimula y que "espera que lo nombre" (Maturo 36). Pero, al mismo tiempo, la nueva realidad le causa una cierta incertidumbre de los signos importados desde Europa. Y es justamente esa incertidumbre respecto a los signos por la que el autor se ve repetidamente forzado a insistir en que su tarea de autor es narrar la verdad, tal como ocurrieron los hechos y como se presentaron ante sus ojos. La obra de Barco Centenera es un ejemplo excepcional que nos hace entender que la conquista no solo fue una empresa económica, pero que estimuló y generó escritura. La problemática codificación de lo que el autor ha visto y oído se resuelve en la inversión de las pretensiones épico-genéricas y Barco Centenera escenifica su texto como una "afirmación del valor de la escritura (de toda escritura) como empresa que, más allá de los resultados estéticos, configura la única realidad perdurable de los hechos" (Campra 1997, 384). En cuanto al sistema de los géneros literarios, el texto es el resultado atípico de una búsqueda de expresar lo vivido fuera de las categorías comunes, y lo "maravilloso [...] se inserta junto a digresiones morales o autobiográficas, como un modo de dar a conocer esa región casi puesto en olvido" (Navascués 75). 


\section{CONCLUSIÓN}

La historia de la cuenca rioplatense alrededor del año 1600 no provee mucho material a los autores con pretensiones épicas. La conquista de esa región no favorece el desarrollo de mitos y leyendas, las sirenas rioplatenses entonan lamentos poco prometedores, y la euforia de las crónicas y de la épica de aquel entonces dejaba paso a un mundo rioplatense mucho menos épico y heroico. No obstante, La Argentina es una epopeya que tematiza esa historia desengañadora. Aunque Barco Centenera pretende imitar la forma de la épica tradicional, constatamos que el nivel de la bistoire de ese texto narrativo es un colorido ramo de flores que no se puede fácilmente encajar en la tradición discursiva del género épico en la primera Edad Moderna. Es posiblemente el choque entre las expectativas épicas, promovido por la gesta de la conquista, y la realidad de la conquista de esa región, que empuja a nuestro autor a construir un texto que no se caracteriza ni por su conservación ni por su superación del género épico, sino más bien por una adaptación -humorística, irónica, hiperbólica- a la realidad histórica. Frente al desengaño de la conquista del Río de la Plata -vacío heroico-, el exaltado heroísmo cede lugar a lo cotidiano, lo subalterno y lo anecdótico. Así, con su experiencia personal -de la que resulta la legitimación de lo narrado- y su obstinado impulso de escribir, Barco Centenera disuelve la relación entre épica y poder, tematizando el lado oscuro de la conquista del Nuevo Mundo rioplatense. En el panorama de la épica, el texto "posee una impar originalidad realista $[y]$ humorística [...] que le permite fundar un imaginario y un mundo novelesco propio" (Maturo 43) que llena el vacío heroico. Ese vacío se llena, además, con la voz del narrador autorreflexivo que aporta una visión subalterna de los hechos de la Conquista. La Argentina desafía en lo extremo las expectativas épicas y las exigencias literarias que los poeta-soldados llevaron del Viejo al Nuevo Mundo rioplatense. Con su tono irónico-anecdótico, la voz épica aporta otro punto de vista a la historiografía de América, invirtiendo el aspecto central de la épica -heroicidad- y combinándolo con el tópico de lo maravilloso y del asombro ante lo nuevo del Nuevo Mundo rioplatense.

\section{OBRAS CITADAS}

Barco Centenera, Martín del. Argentina y conquista del Río de la Plata. Ed. Silvia Tieffemberg. Buenos Aires: UBA, 1998.

Beauchesne, Kim. "La glorificación de la periferia del Nuevo Mundo: representaciones de Cabeza de Vaca en La Argentina (1602) de Martín del Bar- 
co Centenera y otros textos fundacionales del Río de la Plata”. Los géneros poéticos del Siglo de Oro: centros y periferias. Eds. Rodrigo Cacho Casal y Anne Holloway. Woodbridge: Tamesis, 2013. 217-32.

Campra, Rosalba. "Martín del Barco Centenera, Juan María Gutiérrez, Menéndez y Pelayo: lecturas al través”. Río de la Plata: Culturas 15.16 (1992): 285-99.

Campra, Rosalba. "Crónica de un encubrimiento: La Argentina de Martín del Barco Centenera”. Atípicos en la literatura latinoamericana. Ed. Noé Jitrik. Buenos Aires: UBA, 1997. 373-93.

Carilla, Emilio. El Romanticismo en la América Hispánica. Madrid: Gredos, 1958. Chang-Rodríguez, Raquel. "Aquí, ninfas del sur, venid ligeras": voces poéticas virreinales. Madrid: Iberoamericana, 2008.

Curia, Beatriz Elena. "Historia e imaginación poética en los orígenes de la literatura argentina: Luis de Miranda, Martín del Barco Centenera, Ruy Díaz de Guzmán”. Río de la Plata: Culturas 11.12 (1991): 77-87.

Ercilla y Zúñiga, Alonso. La Araucana. Ed. Isaías Lerner. Madrid: Cátedra, 2006. Friedlein, Roger. Kosmovisionen. Inszenierungen von Wissen und Dichtung im Epos der Renaissance in Frankreich, Portugal und Spanien. Stuttgart: Steiner, 2014. Greenblatt, Stephen. Marvelous Possessions: The Wonder of the New World. Chicago: University of Chicago Press, 1992.

Gutiérrez, Juan María. "Estudio sobre La Argentina y conquista del Río de la Plata y sobre su autor don Martín del Barco Centenera". De la poesía y elocuencia de las tribus de América y otros textos. Eds. Juan G. Gómez García y Horacio Jorge Becco. Caracas: Ayacucho, 2006. 21-43.

Hempfer, Klaus. "Die potentielle Autoreflexivität des narrativen Diskurses und Ariosts Orlando Furioso". Erzählforschung. Ed. Eberhard Lämmert. Stuttgart: Metzler, 1982. 130-56.

Maturo, Graciela: "Humanismo y denuncia en la épica cómica de Martín del Barco Centenera”. Relectura de las crónicas coloniales del Cono Sur. Ed. Graciela Maturo. Buenos Aires: Universidad del Salvador-CoNICET, 2004. 31-73.

Mazzotti, José Antonio. "Epic Voices: Non-encounters and Foundation Myths". Literary Cultures of Latin America: A Comparative History, III: Latin American Literary Culture: Subject to History. Eds. Mario J. Valdés y Djelal Kadir. Oxford: Oxford UP, 2004. 3-19.

Navascués, Javier de. "Monstruos de ultramar y reinos imaginarios en Argentina y conquista del Río de la Plata de Martín del Barco Centenera". Romance Notes 55 (2015): 73-82. 
Ortiz Gambetta, Eugenia: "Heteroglosia y tradiciones discursivas: formas burlescas en la épica de M. del Barco Centenera". Hipogrifo 4.1 (2016): 65-86.

Peña, Margarita. "La poesía épica en la Nueva España (siglos XVI, XVII y XVIII)". Conquista y contraconquista: la escritura del Nuevo Mundo. Eds. Julio Ortega y José Amor y Vázquez. México: Colegio de México, 1994. 289-301.

Quint, David. Epic and Empire: Politics and Generic Form from Virgil to Milton. Princeton: Princeton UP, 1993.

Rosenblat, Ángel. El nombre de la Argentina. Buenos Aires: Eudeba, 1964.

Serna, Mercedes. "Introducción”. Poesía colonial hispanoamericana. Ed. Mercedes Serna. Madrid: Cátedra, 2004. 11-50.

Tieffemberg, Silvia. "Disputas y debates en torno a un poema: La Argentina de Barco Centenera". Atípicos de la literatura argentina. Ed. Noé Jitrik. Buenos Aires: UBA, 1997. 365-72.

Tieffemberg, Silvia. "El tópico de la guerra de Jerusalén en Luis de Miranda y Martín del Barco Centenera". Hipogrifo 5.2 (2017): 283-94. 